Case Report

\title{
Ectopic Molar Pregnancy: Diagnostic Efficacy of Magnetic Resonance Imaging and Review of the Literature
}

\author{
Yasushi Yamada, ${ }^{1}$ Satoshi Ohira, ${ }^{1}$ Teruyuki Yamazaki, ${ }^{2}$ and Tanri Shiozawa ${ }^{1}$ \\ ${ }^{1}$ Department of Obstetrics and Gynecology, Shinshu University School of Medicine, 3-1-1 Asahi, Matsumoto 390-8621, Japan \\ ${ }^{2}$ Department of Obstetrics and Gynecology, Iida Municipal Hospital, 438 Yawatamachi, Iida 395-8502, Japan \\ Correspondence should be addressed to Satoshi Ohira; osatoshi@shinshu-u.ac.jp
}

Received 19 July 2016; Accepted 7 August 2016

Academic Editor: Yoshio Yoshida

Copyright (c) 2016 Yasushi Yamada et al. This is an open access article distributed under the Creative Commons Attribution License, which permits unrestricted use, distribution, and reproduction in any medium, provided the original work is properly cited.

\begin{abstract}
Ectopic molar pregnancy is extremely rare, and preoperative diagnosis is difficult. Our literature search found only one report of molar pregnancy diagnosed preoperatively. Moreover, there is no English literature depicting magnetic resonance image (MRI) findings of ectopic molar pregnancy. We report a case of ectopic molar pregnancy preoperatively diagnosed using MRI. A literature review of 31 cases of ectopic molar pregnancy demonstrated that lesions have been found in the fallopian tube (19 cases, $61 \%)$, ovary ( 5 cases, $16 \%$ ), cornu (3 cases, $10 \%$ ), peritoneum ( 2 cases, $6 \%$ ), uterine cervix ( 1 case, $3 \%$ ), and cesarean scar ( 1 case, $3 \%)$. Abdominal pain and abnormal vaginal bleeding were reported in $70 \%$ and $61 \%$ of the patients, respectively. Twenty-one cases (67\%) presented with rupture and hemoperitoneum. All patients underwent surgical resection or dilatation and curettage. Methotrexate therapy was performed in one case because residual trophoblastic tissue was suspected. A second operation was performed in one case of ovarian molar pregnancy because serum hCG levels increased again after primary focal ovarian resection. No patients developed metastatic disease or relapsed. These findings suggest the prognosis of ectopic molar pregnancy to be favorable.
\end{abstract}

\section{Introduction}

Gestational trophoblastic disease (GTD) consists of hydatidiform mole, choriocarcinoma, placental site trophoblastic tumor, and epithelioid trophoblastic tumor. Because the majority of GTD cases occur in the uterus, ectopic molar pregnancy is extremely rare. Gillespie et al. estimated that the incidence of ectopic GTD is 1.5 per one million births in the UK [1]. Preoperative diagnosis of ectopic molar pregnancy is difficult, and our literature search found only one report of molar pregnancy diagnosed preoperatively [2]. Moreover, there is no English literature depicting magnetic resonance image (MRI) findings of ectopic molar pregnancy. Here, we report the first case of ectopic molar pregnancy preoperatively diagnosed using MRI, with a review of the literature.

\section{Literature}

We performed a review of all ectopic molar pregnancy cases published in English and Japanese between 1960 and 2014. All studies were obtained from Medline using the terms "ectopic molar pregnancy", and from references of the articles. All articles without an abstract or with unavailable full text were excluded. We identified 26 articles reporting 31 cases of ectopic molar pregnancy [2-27] (Table 1).

\section{Clinical Case}

We recently observed a 33-year-old, gravida 3 para 2, woman who visited our hospital with a complaint of amenorrhea for 8 weeks and 3 days since her last menstrual period. Her blood pressure was $104 / 76 \mathrm{mmHg}$, with pulse of 68 beats per minute. Her abdomen was soft and she had no tenderness on palpation. On vaginal examination, the uterus was asymmetrically enlarged. Transvaginal ultrasonography (TVUS) revealed an empty endometrial cavity and right cornual hyperechoic mass $(5 \mathrm{~cm})$ with multiple vesicles (Figure 1 ). Serum beta human chorionic gonadotropin $(\beta$-hCG) level was $66,400 \mathrm{ng} / \mathrm{mL}$. Because molar ectopic pregnancy was suspected and her vital signs were stable, MRI was performed. MRI revealed a $5 \mathrm{~cm}$ mass on the right cornu, of isosignal 


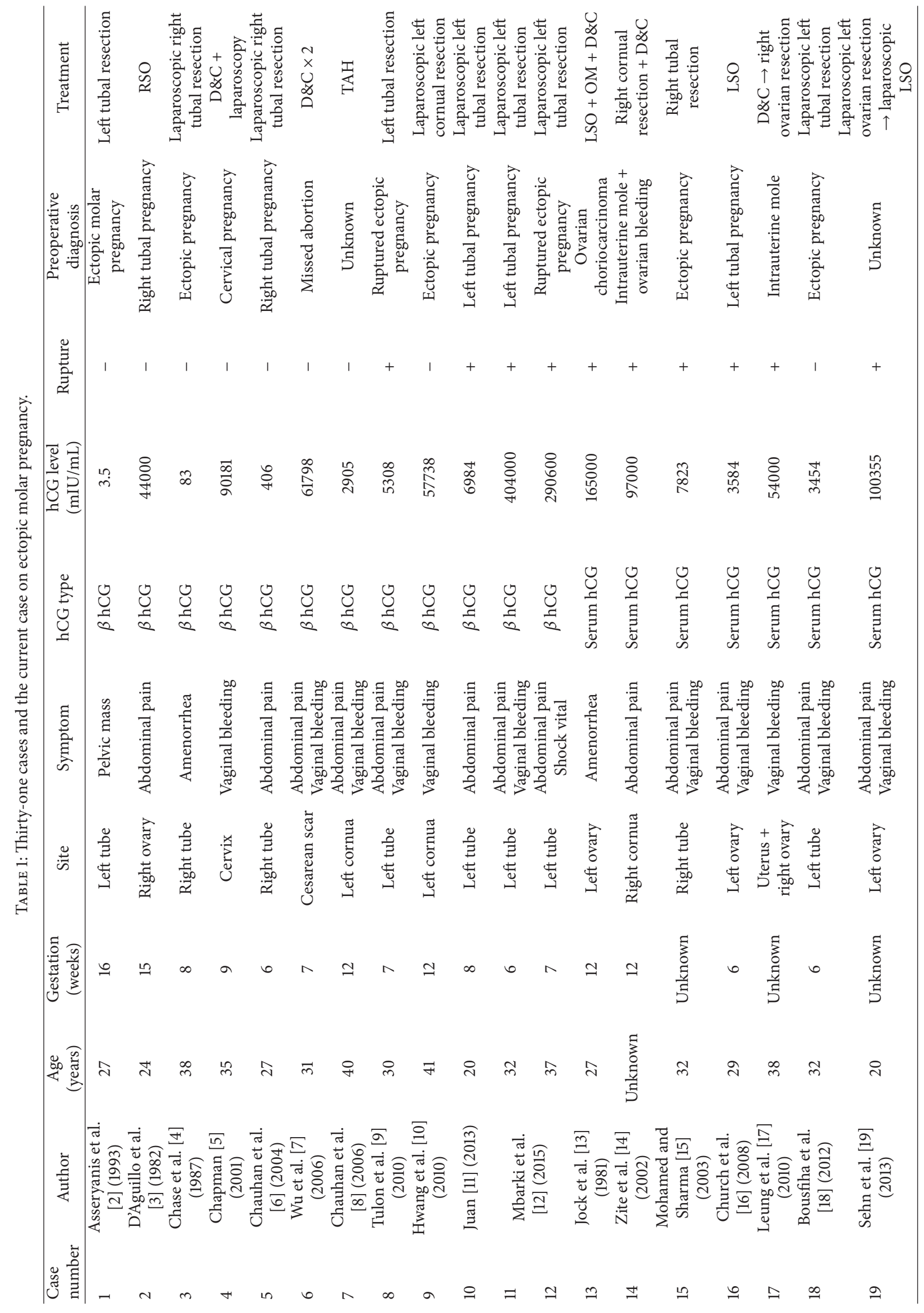




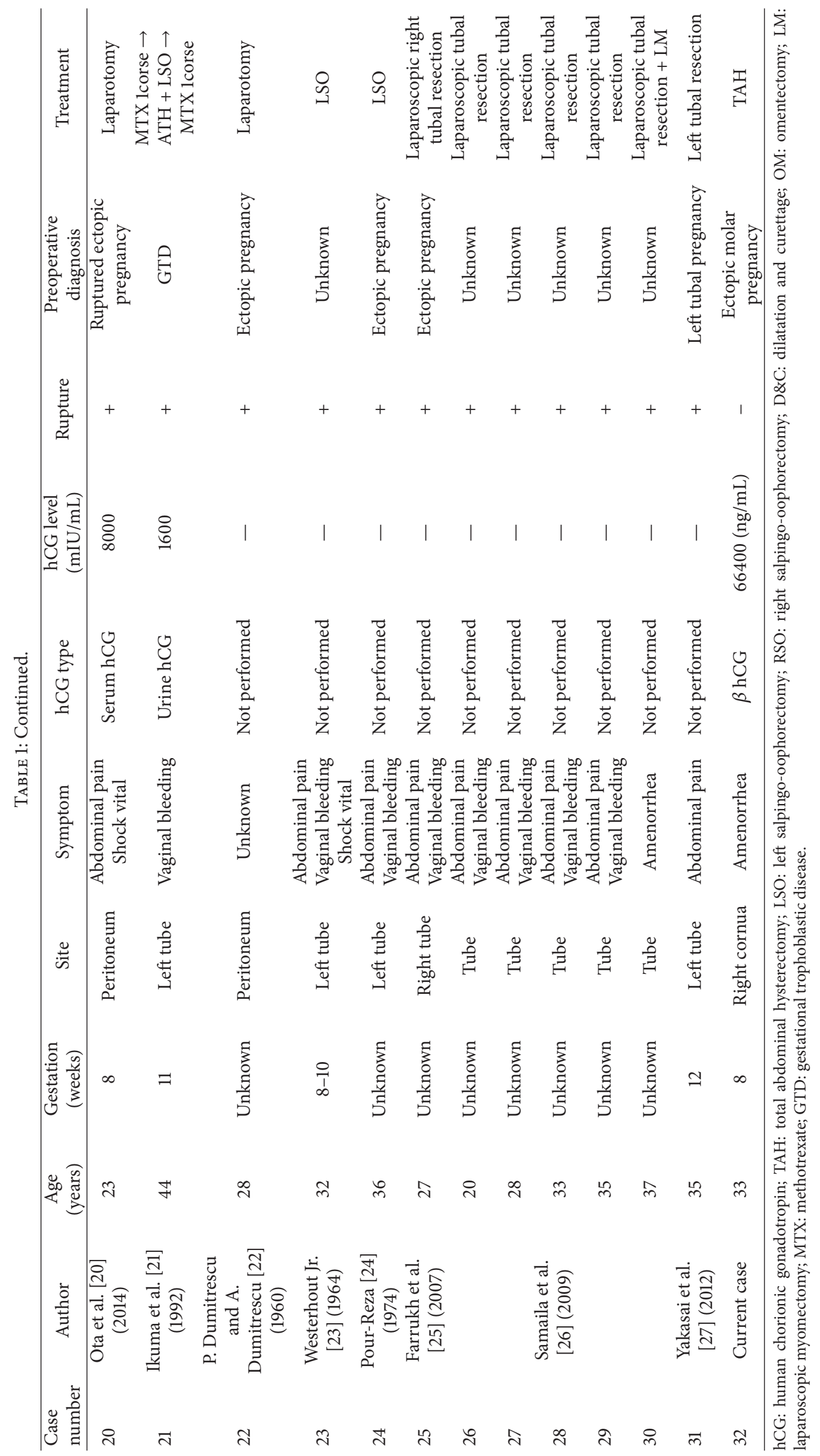




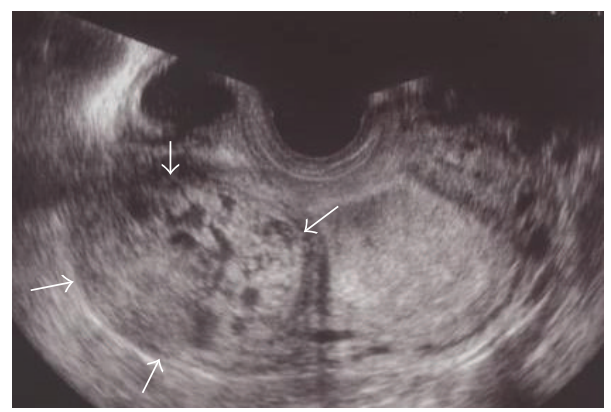

Figure 1: Transvaginal ultrasonographic image at 8 weeks of gestation. A hyperechoic mass $(5 \mathrm{~cm})$ in the right cornu containing multiple vesicles (arrows).

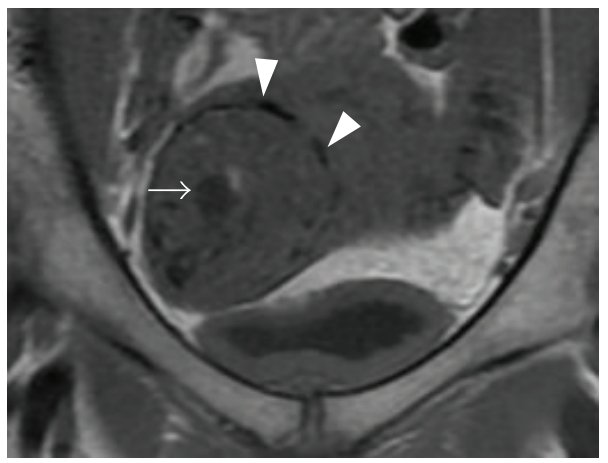

(a)

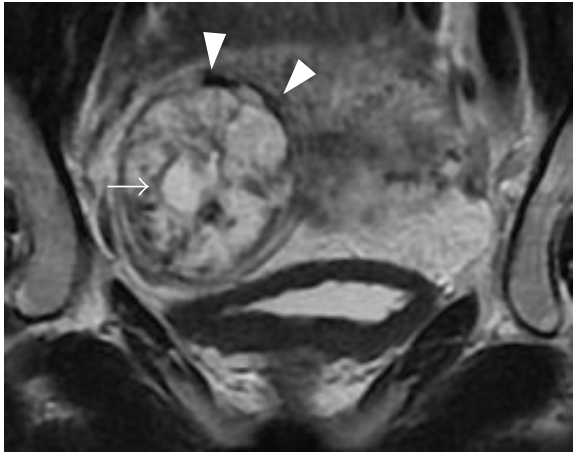

(b)

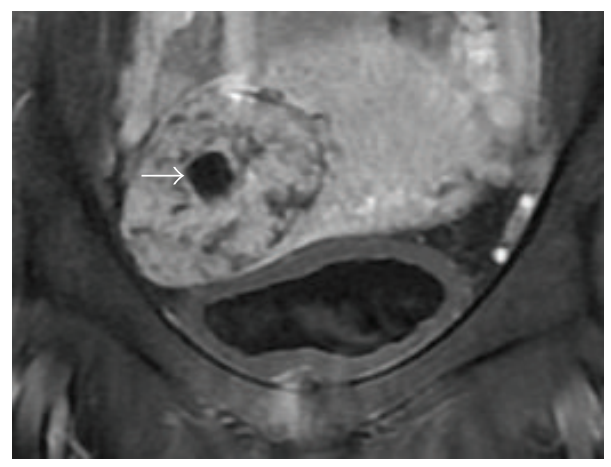

(c)

Figure 2: Coronal MRI images. (a) T1-WI shows an isosignal intensity mass in the right cornu. The mass includes a cyst (arrow) and shows low signal intensity. Several flow voids (arrow heads) are observed at the edge of the mass. (b) T2-WI. The mass and cyst (arrow) show high signal intensity. Several flow voids (arrow heads) are observed at the edge of the mass. (c) Gadolinium-enhanced and fat-suppressed T1-WI demonstrates a well-enhanced mass and clear margins. Arrow indicates the cyst.

intensity on T1-weighted images (T1-WI) and high signal intensity on T2-weighted images (T2-WI). The mass included vesicles with low signal intensities on T1-WI and high signal intensities on T2-WI, suggesting hydropic villi. The mass showed strong gadolinium contrast enhancement, and its margins were clear. Several flow voids were observed at the edge of the mass (Figure 2).

According to these findings, a preoperative diagnosis of ectopic molar pregnancy in the right uterine cornu was made. Because the patient no longer had any wish for a baby, an abdominal hysterectomy was performed. We chose not a laparoscopic surgery but a laparotomy to avoid rupture of enlarged uterine cornu during removing of the uterus through the vagina. On laparotomy, a dark-blue mass with increased vascularity in the right uterine cornu was noted (Figure 3(a)). Both adnexa were normal, and there was no hemoperitoneum. Total abdominal hysterectomy was performed because the patient and her husband did not wish to preserve fertility. Grossly, cut sections of the uterus showed a dark-red $4 \mathrm{~cm}$ mass with small vesicles in the right cornu. The uterus had no malformation such as unicornuate or bicornuate uterus. On pathology, chorionic villi with focal trophoblastic proliferation and hydropic change were observed. There was no cistern formation. A few proliferating 


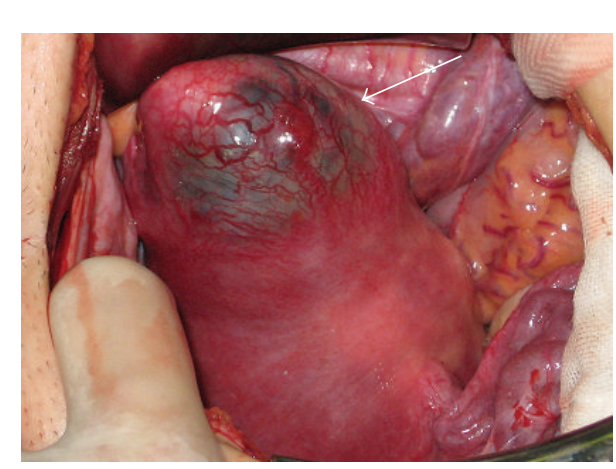

(a)

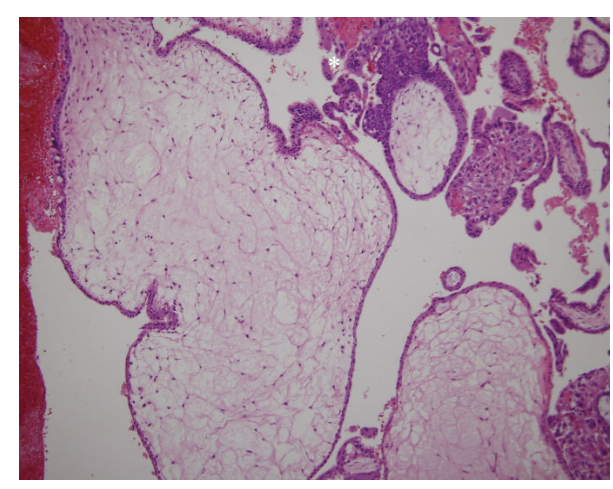

(b)

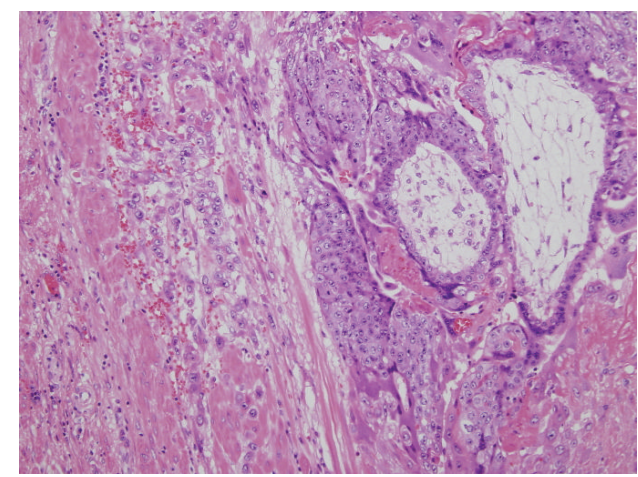

(c)

Figure 3: (a) Photograph of the uterus during laparotomy. A dark-blue mass is seen in the right cornu, with increased vascularity (arrow). (b) Enlarged hydropic villi and focal trophoblastic proliferation (asterisk) are observed. There is no cistern formation. A few proliferating stromal cells are observed but degeneration is not noted. (c) Invasion of villi and trophoblasts to the uterine myometrium. The trophoblastic proliferation is variable.

stromal cells were observed but degeneration was not noted (Figure 3(b)). Invasion of trophoblasts to the myometrium was noted (Figure $3(\mathrm{c})$ ). The postoperative diagnosis was ectopic invasive mole in the right cornu. Systemic computed tomography was performed after operation and revealed no metastatic lesion. The patient was followed up weekly or biweekly, and her $\beta$-hCG level was negative 8 weeks postoperatively. The patient has been free from relapse for 60 months.

\section{Results (Table 1)}

Of the 31 cases reviewed, the mean age was 31.3 years (20 to 44 years), and the lesions were found in the fallopian tube (19 cases, 61\%), ovary (5 cases, 16\%), cornu (3 cases, 10\%), peritoneum ( 2 cases, $6 \%)$, uterine cervix ( 1 case, $3 \%)$, and cesarean scar (1 case, 3\%). Abdominal pain and abnormal vaginal bleeding were reported in $70 \%$ and $61 \%$ of the patients, respectively. Twenty-one cases $(67 \%)$ presented with rupture and hemoperitoneum. Serum $\beta$-hCG levels in 12 cases and serum hCG levels in 8 patients ranged within 3.5$404,000 \mathrm{mIU} / \mathrm{mL}$ and 3,454-165,000 $\mathrm{mIU} / \mathrm{mL}$, respectively. All patients underwent operation or dilatation and curettage. A second operation was needed in one ovarian molar pregnancy case because serum hCG levels increased again after primary focal ovarian resection. Methotrexate therapy was performed in one case because residual trophoblastic tissue was suspected. None of the patients developed metastatic disease or relapsed.

\section{Discussion}

Preoperative diagnosis of ectopic molar pregnancy is difficult, and we found only one reported case. Asseryanis et al. preoperatively detected a left tubal molar pregnancy using transvaginal color-flow Doppler, revealing an arteriovenous shunt flow of both the tumor and myometrium [2]. However, the efficacy of transvaginal color-flow Doppler in the diagnosis of ectopic molar pregnancy remains controversial [28]. We suspected cornual molar pregnancy because transvaginal ultrasonography revealed a mass with small vesicles in the right cornu, which is a typical finding of molar pregnancy. MRI revealed a right cornual mass with isosignal intensity on T1-weighted images (T1-WI) and high signal intensity on T2-weighted images (T2-WI). In addition, small vesicles in the mass showed low signal intensities on T1-WI and high signal intensities on T2-WI, which suggested hydropic villi. Distinguishing between ectopic molar pregnancy and choriocarcinoma or "ordinary" ectopic pregnancy is important. Ha et al. reported four important MRI findings for 
the differential diagnosis between uterine choriocarcinoma and uterine invasive mole: (i) the tumor margin is welldefined in choriocarcinoma and ill-defined in invasive mole; (ii) the hyperintensity pattern on T1-WI is nodular in choriocarcinoma and scattered in invasive mole; (iii) intratumoral vascularity is absent or minimal in choriocarcinoma due to severe central necrosis and hemorrhage, whereas intratumoral vascularity is increased and the tumor is densely enhanced in invasive mole; and (iv) invasive mole has molar tissue-like tiny cystic lesions within the mass [29]. Although the disease site differed, their suggestions may be useful for diagnosing ectopic molar pregnancy. In our case, molar tissue-like tiny cystic lesions, intratumoral hypervascularity, and dense enhancement were observed. We believe that MRI is a powerful tool for diagnosis of ectopic molar pregnancy. However, there may have been several cases in which MRI was not performed due to shock induced by rupture.

The rate of rupture and hemoperitoneum in cases of molar ectopic pregnancy rupture was $67 \%$. Berlingieri et al. and Frates et al. reported rates of ruptured normal ectopic pregnancy of $29.5 \%$ and $25.2 \%$, respectively [30, 31], demonstrating that the rate of molar ectopic pregnancy rupture was significantly higher than that of normal ectopic pregnancy. This may be due to the higher invasive ability of trophoblasts in gestational trophoblastic disease compared with trophoblasts in normal pregnancy.

The serum $\beta$-hCG levels in 12 cases and serum hCG levels of 8 patients ranged within $3.5-404,000 \mathrm{mIU} / \mathrm{mL}$ and 3,454-165,000 mIU/mL, respectively. Frates et al. reported that the serum hCG levels of 225 normal ectopic pregnancy ranged within $7-107,949 \mathrm{mIU} / \mathrm{mL}$ [31]. Tasha et al. reported 18 cases of ectopic gestational trophoblastic disease in 100 cases of ectopic pregnancy. The hCG levels of normal ectopic pregnancy were $1,256-13,494 \mathrm{mIU} / \mathrm{mL}$, partial mole $6,642-$ $15,678 \mathrm{mIU} / \mathrm{mL}$, and complete mole 7,920-24,733 mIU/mL. Furthermore, cases of intrauterine molar pregnancy are known to have higher hCG levels than normal pregnancies. Although Chauhan et al. suggested that implantation in the fallopian tube might preclude adequate vascularization and lead to low hCG levels in ectopic molar pregnancy [6], these reports suggested that ectopic molar pregnancy cannot be distinguished from normal ectopic pregnancy by hCG levels alone. Because none of the patients developed metastatic disease or relapsed, the prognosis of molar ectopic pregnancy is suggested to be favorable.

\section{Competing Interests}

The authors declare that they have no competing interests.

\section{References}

[1] A. M. Gillespie, E. A. Lidbury, J. A. Tidy, and B. W. Hancock, "The clinical presentation, treatment, and outcome of patients diagnosed with possible ectopic molar gestation," International Journal of Gynecological Cancer, vol. 14, no. 2, pp. 366-369, 2004.

[2] E. Asseryanis, B. Schurz, W. Eppel, R. Wenzl, N. Vavra, and P. Husslein, "Detection of an atypical invasive mole in an ectopic pregnancy by transvaginal color-flow Doppler," American Journal of Obstetrics and Gynecology, vol. 169, no. 6, p. 1656, 1993.

[3] A. F. D’Aguillo, M. I. Goldberg, M. Kamalamma, S. Eugene Yuliano, and J. T. Scully, "Primary ovarian hydatidiform mole," Human Pathology, vol. 13, no. 3, pp. 279-281, 1982.

[4] J. S. Chase, J. H. Check, K. Nowroozi, and C. H. Wu, "Firsttrimester serum levels of the $\beta$-subunit of human chorionic gonadotropin in a tubal molar pregnancy," American Journal of Obstetrics and Gynecology, vol. 157, no. 4, part 1, p. 910, 1987.

[5] K. Chapman, "Cervical pregnancy with hydatidiform mole," Acta Obstetricia et Gynecologica Scandinavica, vol. 80, no. 7, pp. 657-658, 2001.

[6] S. Chauhan, M. P. Diamond, and D. A. Johns, "A case of molar ectopic pregnancy," Fertility and Sterility, vol. 81, no. 4, pp. 1140$1141,2004$.

[7] C.-F. Wu, C.-Y. Hsu, and C.-P. Chen, "Ectopic molar pregnancy in a cesarean scar," Taiwanese Journal of Obstetrics and Gynecology, vol. 45, no. 4, pp. 343-345, 2006.

[8] M. B. Chauhan, P. Chaudhary, P. Dahiya, K. Sangwan, and J. Sen, "Molar cornual ectopic pregnancy," Acta Obstetricia et Gynecologica Scandinavica, vol. 85, no. 5, pp. 625-626, 2006.

[9] B. Tulon, R. Vandana, P. Subrat, and S. Pallab, "Ectopic molar pregnancy: a rare entity, Journal of Reproduction \& Infertility, vol. 11, pp. 201-203, 2010.

[10] J. H. Hwang, J. K. Lee, N. W. Lee, and K. W. Lee, "Molar ectopic pregnancy in the uterine cornus," Journal of Minimally Invasive Gynecology, vol. 17, no. 2, pp. 239-241, 2010.

[11] C.-W. Juan, "Fallopian tube invasive molar disease," International Journal of Gynecology and Obstetrics, vol. 122, no. 2, pp. 161-162, 2013.

[12] C. Mbarki, E. Jerbi, N. Hsayaoui, F. Zouari, E. Ben Brahim, and H. Oueslati, "Molar tubal ectopic pregnancy: report of two cases," Journal of Obstetrics and Gynaecology Research, vol. 41, no. 6, pp. 985-988, 2015.

[13] D. E. Jock, P. E. Schwartz, and L. Portnoy, "Primary ovarian hydatidiform mole: addition of a sixth case to the literature," Obstetrics \& Gynecology, vol. 58, no. 5, pp. 657-660, 1981.

[14] N. B. Zite, G. H. Lipscomb, and K. Merrill, "Molar cornual ectopic pregnancy," Obstetrics and Gynecology, vol. 99, no. 5, pp. 891-892, 2002.

[15] A. A. W. Mohamed and S. D. Sharma, "Fallopian tube hydatidiform mole," Journal of Obstetrics and Gynaecology, vol. 23, no. 3, pp. 330-331, 2003.

[16] E. Church, L. Hanna, F. New, A. Uku, H. Awad, and A. J. S. Watson, "Ovarian molar pregnancy," Journal of Obstetrics and Gynaecology, vol. 28, no. 6, pp. 660-661, 2008.

[17] F. Leung, J.-J. Terzibachian, and C. Lassabe, "One mole may hide another: the case of an ovarian hydatidiform mole coexistent with intrauterine hydatidiform mole," European Journal of Obstetrics Gynecology and Reproductive Biology, vol. 148, no. 1, pp. 98-99, 2010.

[18] N. Bousfiha, S. Erarhay, A. Louba et al., "Ectopic molar pregnancy: a case report," Pan African Medical Journal, vol. 11, article 63, 2012.

[19] J. K. Sehn, L. M. Kuroki, M. M. Hopeman, R. E. Longman, C. P. McNicholas, and P. C. Huettner, "Ovarian complete hydatidiform mole: case study with molecular analysis and review of the literature," Human Pathology, vol. 44, no. 12, pp. 2861-2864, 2013.

[20] H. Ota, C. Oda, M. Hayashi, T. Mikoshiba, and M. Kushima, "Rare case of peritoneal complete hydatidiform mole," Journal 
of Obstetrics and Gynaecology Research, vol. 40, no. 4, pp. 11541156, 2014.

[21] K. Ikuma, I. Okada, T. Shiotani, H. Shibahara, and T. Takemura, "Invasive hydatidiform mole in the fallopian tube: report of a case," Nihon Sanka Fujinka Gakkai Zasshi, vol. 44, no. 9, pp. 1189-1192, 1992.

[22] P. Dumitrescu and A. Dumitrescu, "On a case of primary abdominal molar pregnancy," Rumanian Medical Review, vol. 4, pp. 83-84, 1960.

[23] F. C. Westerhout Jr., "Ruptured tubal hydatidiform mole: report of a case," Obstetrics and Gynecology, vol. 23, pp. 138-139, 1964.

[24] M. Pour-Reza, “Tubal hydatidiform mole: report of a case," Acta Medica Iranica, vol. 17, no. 1-2, pp. 43-46, 1974.

[25] A. Farrukh, M. Attia, and H. Furniss, "Tubal hydatidiform mole: an unexpected diagnosis," Journal of Obstetrics and Gynaecology, vol. 27, no. 7, pp. 747-748, 2007.

[26] M. O. Samaila, A. G. Adesiyun, and C. Bifam, "Ruptured tubal hydatidiform mole," Journal of the Turkish German Gynecology Association, vol. 10, no. 3, pp. 172-174, 2009.

[27] I. A. Yakasai, N. Adamu, and H. S. Galadanchi, "Ruptured tubal molar pregnancy," Nigerian Journal of Clinical Practice, vol. 15, no. 4, pp. 491-493, 2012.

[28] P. L. Venturini, F. Gorlero, A. Ferraiolo, M. Valenzano, and E. Fulcheri, "Gestational choriocarcinoma arising in a cornual pregnancy," European Journal of Obstetrics Gynecology and Reproductive Biology, vol. 96, no. 1, pp. 116-118, 2001.

[29] H. K. Ha, J. K. Jung, M. K. Jee et al., "Gestational trophoblastic tumors of the uterus: MR imaging-pathologic correlation," Gynecologic Oncology, vol. 57, no. 3, pp. 340-350, 1995.

[30] P. Berlingieri, G. Bogdanskiene, and J. G. Grudzinskas, "Rupture of tubal pregnancy in the Vilnius population," European Journal of Obstetrics Gynecology \& Reproductive Biology, vol. 131, no. 1, pp. 85-88, 2007.

[31] M. C. Frates, P. M. Doubilet, H. E. Peters, and C. B. Benson, "Adnexal sonographic findings in ectopic pregnancy and their correlation with tubal rupture and human chorionic gonadotropin levels," Journal of Ultrasound in Medicine, vol. 33, no. 4, pp. 697-703, 2014. 


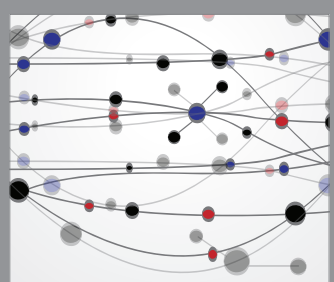

The Scientific World Journal
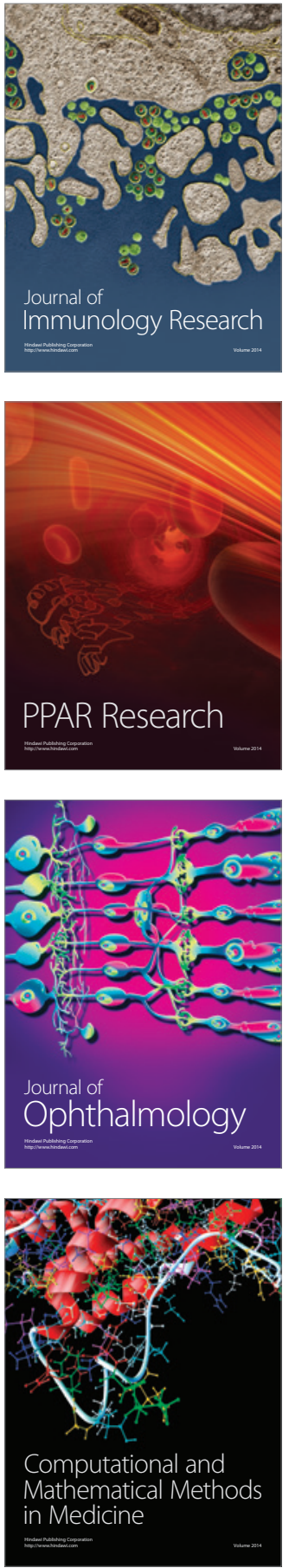

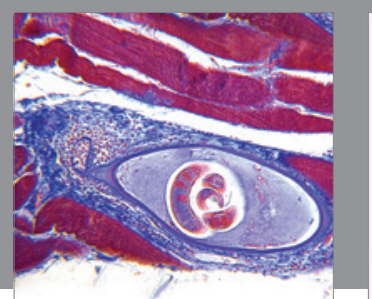

Gastroenterology Research and Practice

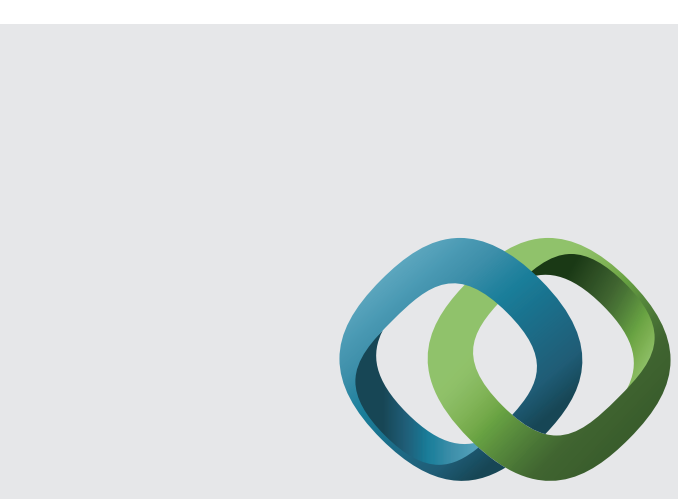

\section{Hindawi}

Submit your manuscripts at

http://www.hindawi.com
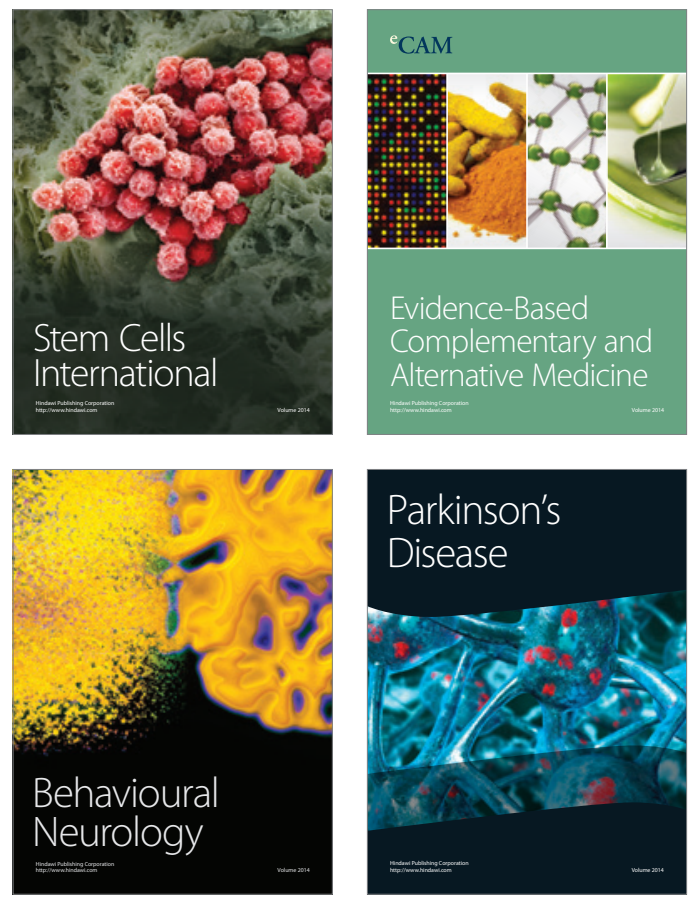
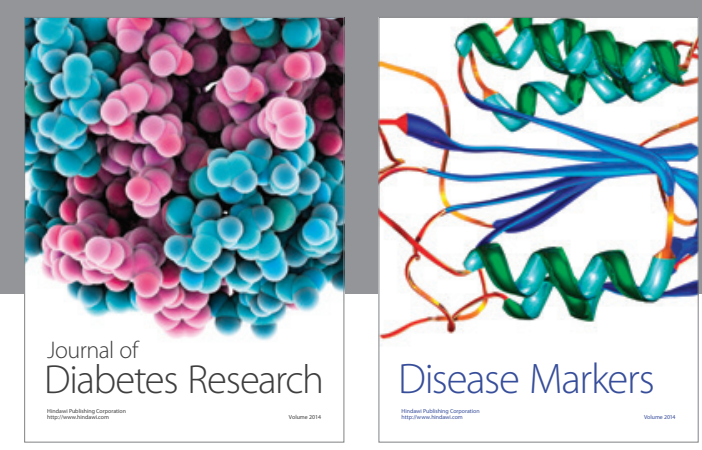

Disease Markers
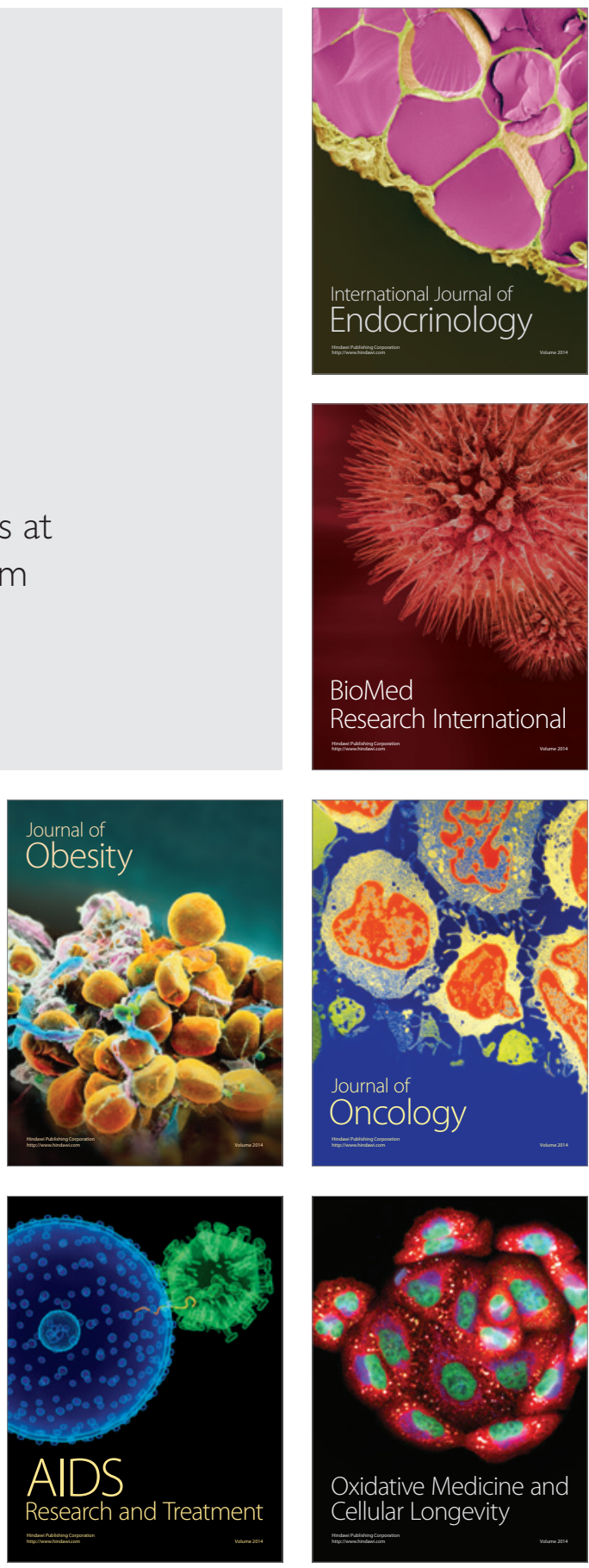